\title{
Uma análise de planos de ensino na perspectiva bachelardiana
}

\section{Adriana Paula Martins ${ }^{1}$ Sueli Teresinha Abreu Bernardes ${ }^{2}$}

\section{Resumo}

Este texto tem por objetivo identificar e analisar os possíveis obstáculos ao conhecimento nos planos de ensino de cursos técnicos integrados ao ensino médio do IFTM, sob a perspectiva teórica da epistemologia de Gaston Bachelard. Parte-se da questão norteadora: quais são os obstáculos ao conhecimento nos planos de ensino dos cursos pesquisados? Para respondê-la utiliza-se uma pesquisa documental e bibliográfica, com abordagem qualitativa, e à análise de significados. Conclui-se que o conhecimento utilitário e a transmissão de conhecimentos podem constituir-se em obstáculos ao saber.

Palavras-chave: Obstáculo epistemológico; Cursos técnicos integrados; Epistemologia bachelardiana.

\begin{abstract}
This paper aims to identify and analyze potential barriers to knowledge in educational plans for technical courses integrated into the high school of IFTM, from the theoretical perspective of Gaston Bachelard epistemology. It starts with the guiding question: what are the obstacles to knowledge in educational plans of surveyed courses? To answer it is used a documental and bibliographic research, with a qualitative approach, and the analysis of meanings. It is concluded that the utility knowledge and the transmission of knowledge may form obstacles to knowledge.
\end{abstract}

Keywords: Epistemological obstacle; Integrated technical courses; Bachelardian epistemology.

\footnotetext{
${ }^{1}$ Graduada e licenciada em Pedagogia, especialista em Psicopedagogia Institucional e Inspeção Escolar, mestra em Educação pela UNIUBE, na linha de pesquisa Cultura e processos educativos.

${ }^{2}$ Doutora em Educação e mestra em Educação Brasileira pela UFG, mestra em Ciências e Valores Humanos pela UNIUBE, licenciada em Filosofia, professora titular da UNIUBE.
} 
Introdução

$\mathrm{N}$

esta investigação, o objeto foi pesquisado em uma instituição de ensino que faz parte da Rede de Educação Profissional e Tecnológica do Governo Federal do Brasil. Esse tipo de educação tem origem em nosso país no período colonial, baseado na economia da agroindústria açucareira, na qual a mão de obra procedia dos índios e negros, os quais foram os primeiros aprendizes de ofícios.

Ao longo dos anos a educação profissional atendeu a orientações do Governo Federal e foi se constituindo juntamente com a história do Brasil. Tal composição tem seu marco legal a partir de 1909, ano em que foram criadas as Escolas de Aprendizes Artífices. Os Liceus de Artes e Ofícios datam de 1937 e, um pouco mais tarde, as Escolas Industriais e Técnicas surgiram a partir de 1942. No ano de 1978 foram criados os primeiros Centros Federais de Educação Tecnológica. O Sistema Nacional de Educação Tecnológica se inicia em 1994 e a Universidade Tecnológica em 2003. No ano de 2008 os CEFETs e algumas escolas técnicas vinculadas às universidades federais transformaram-se em Institutos Federais de Educação, Ciência e Tecnologia.

Schmidt (2010) enfatiza as análises dessa modalidade de ensino com relação a sua importância para a urbanização e industrialização do Brasil, com a formação de profissionais e, sobretudo, com a forma como está ocorrendo esse processo de formação. Uma vez que a educação foi um suporte para preparar profissionalmente a população para atender as demandas da economia em diferentes épocas.

Fundamentados nas discussões de Frigotto (2007, 2009 e 2011), Kuenzer (1997) e Ciavatta e Ramos (2011) direcionamos nosso olhar para alguns recortes da história da educação profissional. Esses pesquisadores tecem suas discussões sobre a realidade da educação brasileira com reflexões críticas sobre as finalidades das propostas educacionais do passado, do presente e a relação existente entre elas. Encontramos nesses estudos a preocupação com a realidade implícita na proposta de criação dos cursos técnicos integrados ao ensino médio e dos institutos federais. Essas propostas, 
de acordo com a compreensão desses estudiosos, estão comprometidas com a dualidade histórica da educação no Brasil.

É tal perspectiva que constitui um de nossos propósitos de pesquisa em um instituto federal. Pensamos que um novo papel, contrário a suas raízes assistencialistas, pode ser assumido pela educação profissional. Atualmente, várias formas de cursos são ofertadas pelos institutos federais aos mais variados sujeitos. Essas instituições consolidam um papel histórico na educação brasileira e abrangem um número cada vez maior da população, oferecendo formação para o trabalho e melhores condições de formação para a vida como um todo. No entanto, essa formação deve ser investigada, uma vez que está intrinsecamente relacionada ao papel histórico exercido pela educação profissional.

Seguindo por tais compreensões, a presente investigação científica tem por objeto de pesquisa um dos cursos ofertados prioritariamente nos institutos federais: os cursos técnicos integrados ao ensino médio. Tais cursos oferecem simultaneamente, de forma integrada, o ensino médio e o ensino profissionalizante. Nessa modalidade de ensino o projeto pedagógico, a matriz curricular, a matrícula e a certificação dos alunos são únicos, de modo a garantir o cumprimento simultâneo das finalidades estabelecidas, tanto para a educação profissional técnica de nível médio quanto para o ensino médio.

Partimos do entendimento de que um educador deve buscar o sentido do que lhe é proposto, do que faz e do alcance do trabalho no qual se insere. Para tanto, mesmo com a experiência vivenciada no cotidiano educacional e das reflexões formuladas, somente ao nos distanciarmos do senso comum podemos compreender e nos aproximar de um espírito científico, segundo a acepção do professor, pesquisador e filósofo francês Gaston Bachelard (18841962).

Nesse contexto, algumas estratégias como analogias, metáforas, imagens e modelos geralmente são empregadas pelos educadores para facilitar a aprendizagem. No entanto, devemos refletir sobre o tipo de conhecimento formado por meio de tais recursos. Muitas vezes, essas práticas pedagógicas baseadas no senso comum substituem uma cultura do raciocínio 
por esquemas, o que desperta interesse e ao mesmo tempo sedimenta conhecimentos equivocados. Os conceitos construídos por noções advindas dos conhecimentos empíricos do educando ou mesmo nas práticas pedagógicas cotidianas da escola constituem os obstáculos epistemológicos, que se "incrustam no conhecimento não questionado" (BACHELARD, 1996, p.12).

Enquanto fenômenos inerentes ao ato de conhecer, tais obstáculos podem estar presentes nos mais variados momentos do processo educativo. Desde as atividades de planejamento até aquelas voltadas para avaliação podem constituir práticas que bloqueiam o pensamento, impedindo a construção de um novo conhecimento. De acordo com Bachelard (1996), é no âmago do próprio ato de conhecer que os obstáculos epistemológicos aparecem, por uma espécie de imperativo funcional, de lentidões e de conflitos.

Dessa forma, os obstáculos epistemológicos conceituados por Bachelard precisam ser identificados para a devida compreensão do conhecimento construído, por meio do questionamento, da ruptura e da superação. Entendemos que os planos de ensino, objeto da presente pesquisa, expressam as diretrizes do processo de construção do conhecimento. Assim sendo, nos propomos a identificar os princípios e as práticas planejadas nesses documentos pedagógicos que podem configurar-se como obstáculo à construção do conhecimento.

\section{Revisão Bibliográfica}

As discussões sobre a problemática em pesquisa são fundamentadas, sobretudo, nas obras epistemológicas de Bachelard: “A formação do espírito científico: contribuição para uma psicanálise do conhecimento” (1996); “O novo espírito científico" (1978) e "A filosofia do não" (1978). Os conceitos contidos nesses livros giram em torno da construção do conceito científico e da análise da natureza dos obstáculos epistemológicos, tomando exemplos, sobretudo, na história da Ciência do século XVIII. Nessas obras o filósofo afirma, inicialmente, a necessidade de valorização do pensamento científico 
abstrato e aponta a experiência imediata como um obstáculo ao desenvolvimento dessa abstração.

Bachelard entende o conhecimento como uma construção que não pode ser uma linha contínua, mas muitas linhas, sem ligações umas com as outras, que trazem a possibilidade de se criar ou conhecer algo novo. Pensamos que tais reflexões estão estreitamente relacionadas aos seus conceitos de recorrência histórica, de rupturas e de obstáculos epistemológicos.

Seguindo nossas interpretações acerca desse pensamento, percebemos que o objetivo da recorrência histórica é auxiliar o sujeito a vencer os obstáculos epistemológicos, por meio da compreensão psicológica dos conhecimentos primeiros, à luz das compreensões do presente. Sendo assim, todo conhecimento do passado deve passar pelo julgamento das verdades do presente.

Fonseca (2008, p. 385), nesse sentido afirma que

A superação de obstáculos se inicia com uma nova pedagogia, aquela que ele chama de pedagogia científica, na qual o esforço do professor consiste em fazer com que os alunos se afastem da cultura científica adquirida e da percepção apreendida na vida cotidiana pelo senso comum. É impossível educar por simples referência a um passado de educação. É necessário pensar numa ciência em mutação e num pensamento aberto que se renova.

Por tais compreensões o conceito de recorrência histórica está relacionado ao conceito de rupturas. Na leitura de Macedo (2006) entendemos que a epistemologia bachelardiana apregoa que o progresso do saber científico somente é possível a partir de rupturas epistemológicas sucessivas. "Entre o conhecimento comum e o conhecimento científico a ruptura nos parece tão nítida que estes dois tipos de conhecimento não poderiam ter a mesma filosofia [...]" (BACHELARD, 1978, p.45). Compreendemos assim que o desenvolvimento científico ocorre através de momentos de ruptura que separam uma etapa da outra. Bachelard (1978) nos alerta ainda que, essa 
ruptura pode ser identificada entre o senso comum e o conhecimento científico ou mesmo entre saberes científicos de diferentes épocas, ou seja, onde houver um obstáculo epistemológico deverá acontecer uma ruptura.

Para entendermos o conceito de obstáculos epistemológicos, é essencial a discussão acerca da noção de erro. No pensamento bachelardiano, o erro delimita como o sujeito conhece algo, possibilita a dúvida e desconstrói descobertas. Bachelard (1996) posiciona-se sobre a importância de recorrermos aos erros do passado para termos consciência da necessidade de transformação e assim promovermos o que ele chamava de rupturas. Dessa forma, ele é visto como positivo, uma vez que o conhecimento evolui por meio de rupturas com o conhecimento anterior e pela superação dos obstáculos epistemológicos. O erro não deve ser evitado no ato de conhecer e sim conscientizado, pois é a partir dele que o conhecimento passará para outro estágio. O erro, diretamente ligado ao ato de conhecer, foi definido pelo filósofo como sendo simultaneamente condutor para aquisição de novos conhecimentos e obstáculo a ser superado. Por essa valorização atribuída ao erro "[...] talvez seja nele que a historicidade das ciências se manifeste com maior intensidade" (TERNES, 2011, p. 229).

\section{Metodologia}

Quanto à delimitação metodológica optamos por uma pesquisa documental e bibliográfica. A abordagem utilizada é a qualitativa, na perspectiva de Lüdke e André (1986). Assim sendo, o texto que ora apresentamos é descritivo, expositivo e argumentativo.

A obtenção dos dados foi conseguida em contato com os responsáveis por arquivar os documentos no IFTM e por meio de consulta à página virtual do Conselho Superior da referida instituição.

Para a análise dos documentos pareceu-nos apropriado o procedimento de Bicudo (2000) sobre a análise das unidades de significado, uma vez que a autora propõe um trabalho com dados oriundos da descrição de discursos. Em nosso trabalho, utilizamos documentos nos quais os dados já estão descritos. Ou seja, as unidades de significado foram identificadas nos planos de ensino 
dos cursos pesquisados, convergindo as unidades de significado em categorias abertas, entendidas como obstáculos ao conhecimento.

A identificação dos possíveis obstáculos ao conhecimento foi alcançada a partir da interpretação das unidades de significado à luz da epistemologia do filósofo e professor Bachelard (1996).

\section{Resultados e discussões}

Encontramos uma definição para os cursos técnicos integrados ao ensino médio no Decreto $n^{\circ}$ 5.154/04, em que lemos que a educação profissional e tecnológica de nível médio poderá ser ofertada por meio de três formas de articulação: integrada, concomitante e subsequente. A forma de articulação integrada, ou cursos técnicos integrados ao ensino médio é destinada a estudantes que tenham concluído o ensino fundamental e desejam cursar o ensino médio juntamente com um curso profissionalizante na mesma instituição. A articulação da educação profissional concomitante ao ensino médio é oferecida aos concluintes do ensino fundamental, que estejam cursando o ensino médio na mesma instituição ou instituições diferentes. A articulação na forma subsequente é destinada somente aos educandos que tenham concluído o ensino médio e queiram adquirir uma habilitação profissional.

Os cursos técnicos integrados ao ensino médio pesquisados estão entre os trinta e três cursos ofertados no IFTM. Essa modalidade de ensino teve início em 2008, com a criação do curso técnico em informática integrado ao ensino médio ofertado no campus Uberaba. A oferta desse curso foi impulsionada por um dos objetivos da Lei $\mathrm{n}^{\circ} 11.892 / 08$, que regulamenta a oferta da educação profissional técnica de nível médio prioritariamente na forma de cursos integrados nos institutos federais:

[...] I - ministrar educação profissional técnica de nível médio, prioritariamente na forma de cursos integrados, para os concluintes do ensino fundamental e para o público da educação de jovens e adultos [...] (BRASIL, 2008). 
De acordo com o Relatório de Prestação de Contas do ano de 2012, são ministrados 9 cursos técnicos integrados na instituição pesquisada, quais sejam: Agroindústria, Informática, Eletrônica, Comércio, Agropecuária, Manutenção e Suporte em Informática, Manutenção e Suporte em Informática.

Para a análise dos dados partimos de nossa compreensão de obstáculo epistemológico, ou seja, tudo aquilo que pode bloquear ou impedir a construção do conhecimento científico. Todavia esse conceito é utilizado para refletirmos sobre as práticas dos professores, expressas nos planos de ensino que podem se configurar em obstáculos à constituição do conhecimento. Com tal entendimento, de acordo com o proposto por Bicudo (2000), e de acordo com nossa análise, nem todos os planos de ensino analisados apresentaram aspectos que podem configurar-se em obstáculo à construção do conhecimento.

Ressaltamos que entre os 147 documentos pedagógicos obtidos, apenas 70 atendiam aos critérios propostos para nossa pesquisa. Dentre esse quantitativo identificamos aspectos que podem configurar-se em obstáculo ao conhecimento em 36 planos de ensino.

A seguir apresentamos o quadro com a análise das unidades de significado identificadas que podem se configurar em obstáculos ao conhecimento, segundo nossa compreensão da epistemologia de Bachelard.

\section{Quadro 1}

Unidades de significado e categorias do conhecimento utilitário identificadas nos planos de ensino

\begin{tabular}{|c|l|}
\hline $\begin{array}{c}\text { Planos } \\
\text { de } \\
\text { ensino }\end{array}$ & \multicolumn{1}{|c|}{ Unidades de significado } \\
\hline A1 & $\begin{array}{l}\text { "[...] possam prosseguir os estudos na busca do aprimoramento } \\
\text { profissional" (p.1). } \\
\text { "Apresentar noções de matemática financeira através de } \\
\text { situações práticas [...]" }\end{array}$ \\
\hline A2 & $\begin{array}{l}\text { "A metodologia de trabalho dará ênfase ao 'aprender fazendo'. } \\
\text { Como se trata de um conteúdo altamente prático, os alunos } \\
\text { serão estimulados em cada aula a realizar uma tarefa prática de }\end{array}$ \\
\hline
\end{tabular}




\begin{tabular}{|c|c|}
\hline $\begin{array}{l}\text { Planos } \\
\text { de } \\
\text { ensino }\end{array}$ & Unidades de significado \\
\hline & $\begin{array}{l}\text { aplicação do conteúdo, procurando aumentar a fixação dos } \\
\text { conteúdos" }\end{array}$ \\
\hline A3 & $\begin{array}{l}\text { "[...] oferecer suporte para que possam prosseguir os estudos } \\
\text { na busca do aprimoramento profissional" }\end{array}$ \\
\hline A4 & $\begin{array}{l}\text { "[...] oferecer suporte para que possam prosseguir os estudos } \\
\text { na busca do aprimoramento profissional" }(2012, \text { p. } 1) \text {. }\end{array}$ \\
\hline A5 & $\begin{array}{l}\text { "[...] oferecer suporte para que possam prosseguir os estudos } \\
\text { na busca do aprimoramento profissional" }\end{array}$ \\
\hline A15 & $\begin{array}{l}\text { "[...] construção do conhecimento científico em estreita } \\
\text { relação com as aplicações tecnológicas e suas implicações } \\
\text { ambientais, sociais, políticas e econômicas" }\end{array}$ \\
\hline A19 & $\begin{array}{l}\text { "Introduzir aos alunos as principais questões conceituais e } \\
\text { metodológicas das disciplinas das Ciências Sociais } \\
\text { indispensáveis à formação básica do ser humano, seu papel no } \\
\text { mercado de trabalho e sua convivência em sociedade, [...]" }\end{array}$ \\
\hline A21 & $\begin{array}{l}\text { "[...] tomando como referência os princípios políticos que } \\
\text { fundamentam a sociedade capitalista na contemporaneidade } \\
{[\ldots] "}\end{array}$ \\
\hline A22 & $\begin{array}{l}\text { "A disciplina de Matemática do Ensino Médio Integrado à } \\
\text { Educação Profissional tem um caráter tanto formativo, que } \\
\text { auxilia a estruturação do pensamento e do raciocínio lógico, } \\
\text { quanto instrumental, utilitário, de aplicação no dia-a-dia, em } \\
\text { outras áreas do conhecimento e nas atividades profissionais". }\end{array}$ \\
\hline A25 & $\begin{array}{l}\text { "Pretende-se no curso de Física do } 3^{\circ} \text { ano do ensino médio } \\
\text { iniciar um processo de construção de um conhecimento efetivo } \\
\text { de eletricidade, contextualizado à vida e à cultura que cerca o } \\
\text { educando. Pretende-se ainda proporcionar meios para que o } \\
\text { educando possa articular os saberes da disciplina tanto com os } \\
\text { processos e equipamentos tecnológicos contemporâneos, } \\
\text { como com as atividades profissionais e cotidianas do mesmo". }\end{array}$ \\
\hline A27 & $\begin{array}{l}\text { "Adequando o conhecimento dos educandos ao mercado de } \\
\text { trabalho atual." }\end{array}$ \\
\hline A29 & $\begin{array}{l}\text { "O objetivo geral da disciplina de Língua Portuguesa é enfocar } \\
\text { o trabalho como princípio educativo [...]" }\end{array}$ \\
\hline A31 & $\begin{array}{l}\text { "[...] apresentá-la como parte imprescindível ao conjunto de } \\
\text { conhecimentos essenciais que permitam ao educando } \\
\text { aproximar-se das várias culturas, propiciando sua integração } \\
\text { no mundo globalizado, ajudando em sua inserção no mercado } \\
\text { de trabalho" }\end{array}$ \\
\hline A32 & “[...] enfocando o trabalho como princípio educativo" \\
\hline A36 & $\begin{array}{l}\text { "Possibilitar a compreensão tanto dos processos químicos em } \\
\text { si, quanto da construção do conhecimento científico em } \\
\text { estreita relação com as aplicações tecnológicas e suas } \\
\text { implicações ambientais, sociais, políticas e econômicas" }\end{array}$ \\
\hline
\end{tabular}




\begin{tabular}{|c|c|}
\hline $\begin{array}{l}\text { Planos } \\
\text { de } \\
\text { ensino }\end{array}$ & Unidades de significado \\
\hline A38 & $\begin{array}{l}\text { "Possibilitar ao educando a identificação, a problematização e } \\
\text { o debate dos valores característicos da Ética relacionando-os } \\
\text { às situações cotidianas e às diretrizes que sustentam o projeto } \\
\text { de código de ética do profissional da área de Informática" } \\
\text { "Resgatar historicamente o conceito de ética e redimensioná- } \\
\text { lo às situações do mundo contemporâneo" }\end{array}$ \\
\hline A40 & $\begin{array}{l}{[\ldots] \text { entendimento e vivencia do lazer frente ao processo de }} \\
\text { trabalho preconizado pelos modelos de produção capitalista" }\end{array}$ \\
\hline A43 & $\begin{array}{l}\text { "[...] com o intuito de fazer com que reveja suas ações e } \\
\text { atitudes diante de sua vida pessoal e profissional, } \\
\text { demonstrando capacidade empreendedora no mercado de } \\
\text { trabalho para a obtenção de resultados positivos" } \\
\text { "Levantamento dos conhecimentos iniciais que cada aluno tem } \\
\text { da disciplina, antes de iniciá-la, através de depoimentos e a } \\
\text { técnica de Brainstorming (tempestade de ideias)" }\end{array}$ \\
\hline A46 & $\begin{array}{l}\text { "O objetivo geral da disciplina de Língua Portuguesa é enfocar } \\
\text { o trabalho como princípio educativo [...]" } \\
\text { "[...] entendendo os princípios das tecnologias da comunicação } \\
\text { e da informação, para associá-las aos conhecimentos } \\
\text { científicos [...]" }\end{array}$ \\
\hline A47 & $\begin{array}{l}\text { "[...] propiciando sua integração no mundo globalizado, } \\
\text { ajudando em sua inserção no mercado de trabalho (2012, } \\
\text { p.01). }\end{array}$ \\
\hline A49 & $\begin{array}{l}\text { "O objetivo geral da disciplina de Língua Estrangeira } \\
\text { Moderna- INGLÊS é enfocar o trabalho como princípio } \\
\text { educativo" }\end{array}$ \\
\hline A50 & "enfocando o trabalho como princípio educativo $[. .] "$. \\
\hline A63 & $\begin{array}{l}\text { "A disciplina de Matemática do Ensino Médio Integrado à } \\
\text { Educação Profissional tem um caráter tanto formativo, que } \\
\text { auxilia a estruturação do pensamento e do raciocínio lógico, } \\
\text { quanto instrumental, utilitário, de aplicação no dia-a-dia, em } \\
\text { outras áreas do conhecimento e nas atividades profissionais" } \\
(2012, \text { p.01). }\end{array}$ \\
\hline A68 & $\begin{array}{l}\text { "Conhecer brevemente a história da Sociologia" "Conhecer a } \\
\text { abordagem sociológica }[\ldots] "\end{array}$ \\
\hline
\end{tabular}

Fonte: Planos de ensino A1 a A70

$\mathrm{Na}$ leitura dos dados de nossa pesquisa percebemos, conforme exposto no Quadro 1, a possível formação do conhecimento utilitário como um obstáculo à construção do saber nas unidades de significado que atribuem a utilidade do conhecimento restrito a formação profissional, para atender aos anseios da sociedade e às demandas do mercado de trabalho. 
O obstáculo do conhecimento utilitário relaciona o saber a uma utilidade prática, atribui ao conhecimento um sentido externo ao sujeito e não à transformação ou a metamorfose proposta por Bachelard. Entendemos que, pela análise realizada dos planos de ensino, o conhecimento é construído para atender a uma utilidade.

Compreendemos que quando designamos os objetos pela sua utilidade procuramos um princípio de explicação, no entanto, estamos nos distanciando do conhecimento real sobre esse objeto.

De acordo com nossos estudos da epistemologia bachelardiana, a própria utilidade atribuída ao conhecimento direciona a formação do saber ao que o filósofo chama de "indução utilitária". Tal indução, por sua vez, leva a generalizações exageradas, as quais são apontadas pelo filósofo Bachelard como outro entrave a construção do conhecimento.

Conceituado por Bachelard (1996), o obstáculo do conhecimento geral é caracterizado pelas leis gerais que bloqueiam o percurso das ideias, pois respondem de forma generalizada sem que haja uma pergunta.

Há de fato um perigoso prazer intelectual na generalização apressada e fácil. A psicanálise do conhecimento objetivo deve examinar com cuidado todas as seduções da facilidade. Só com essa condição pode-se chegar a uma teoria da abstração científica verdadeiramente sadia e dinâmica (BACHELARD, 1996, p.60).

Ao partir da verificação de um fato o impulso utilitário torna-se um conhecimento mutilado, o que muitas vezes leva ao exagero ou a compreensão a partir das leis gerais, o qual acaba se solidificando enquanto saber equivocado ou entrave ao progresso do conhecimento. Ou seja, o utilitarismo do saber induz ao caminho muito longo, em que o sujeito não consegue limitar a utilidade e a valorização de um conhecimento e logo induz a uma supervalorização equivocada. Percebemos que o planejado nas unidades analisadas poderá assumir tal característica utilitária.

Pelos estudos da epistemologia de Bachelard compreendemos que diante do utilitarismo a construção do conhecimento se limita a sua utilidade. 
A partir do momento que essa utilidade é identificada, o saber é estagnado, não há mais necessidade de busca, pois os conhecimentos construídos já são o bastante para atender a tal utilidade.

Entendemos ainda que as análises feitas a partir de uma visão utilitarista e habitual estão muito próximas ao senso comum e à experiência primeira, o que distancia da constituição de um saber científico.

Na formação do espírito científico, o primeiro obstáculo é a experiência primeira, a experiência colocada antes e acima da crítica - crítica esta que é, necessariamente, elemento integrante do espírito científico. Já que a crítica não pôde intervir de modo explícito, a experiência primeira não constitui, de forma alguma, uma base segura (BACHELARD, 1996, p.21).

A experiência primeira ou o primeiro olhar lançado ao objeto não pode proporcionar um conhecimento seguro e livre de erros. No entanto, o saber baseado na experiência primeira conduz a equívocos que podem ser solidificados enquanto conhecimentos, mas que na verdade estão arraigados de obstáculos ao progresso do saber.

O processo educativo, por sua vez, deve romper com uma cultura sedimentada pela vida cotidiana e não afirmá-la. Enquanto o sujeito valoriza a experiência primeira está enfatizando uma cultura a ser retificada.

Para Bachelard (1996) todo conhecimento utilitarista, mesmo que de forma velada, está associado ao empirismo e impregnado de interesses subjetivos distantes da ciência. Para nosso filósofo, é preciso

romper com as considerações pragmáticas. Sistemas inteiros foram fundados sobre considerações utilitárias. Apenas a utilidade é clara. Apenas a utilidade explica. Logo, o verdadeiro deve ser acompanhado do útil. O verdadeiro sem função é um verdadeiro mutilado. E, quando se descobre a utilidade, encontra-se a função real do verdadeiro. Esse modo de ver utilitário é, porém, uma aberração (BACHELARD, 1996, p.101). 
O filósofo-professor enfatiza que no século XVIII o obstáculo do conhecimento utilitário foi perigoso, porque a exploração literária e filosófica da ciência dessa época era muito fácil. No entanto, na construção do conhecimento científico nada pode ser evidente ou gratuito, ao contrário, todo saber é constantemente construído. Identificamos tal reflexão também na proposta pedagógica de Bachelard, na qual o filósofo enaltece a importância do erro. É na relação professor-aluno que os erros do passado, da vida cotidiana, bem como aqueles decorrentes do processo educativo podem ser identificados, por meio do diálogo e da construção conjunta do saber.

De acordo com nossa compreensão, o obstáculo da transmissão de conhecimentos também pode se fazer presente nos planos de ensino analisados, sobretudo no exposto pelas unidades de significado explicitadas no Quadro 2.

\section{Quadro 2}

Unidades de significado e categorias da transmissão do conhecimento identificadas nos planos de ensino.

\begin{tabular}{|c|c|}
\hline $\begin{array}{l}\text { Planos de } \\
\text { ensino }\end{array}$ & Unidades de significado \\
\hline $\mathrm{A} 2$ & $\begin{array}{l}\text { "Capacitar o aluno a }[\ldots] " \\
\text { "Capacitar o aluno a desenvolver }[\ldots] "\end{array}$ \\
\hline A7 & $\begin{array}{l}\text { "[...] são passadas aos alunos, os conceitos sobre os diversos } \\
\text { tópicos a serem tratados" }\end{array}$ \\
\hline A17 & "Possibilitar ao educando a compreensão..." \\
\hline A28 & $\begin{array}{l}\text { "Possibilitar ao educando conhecer e administrar }[\ldots] " \\
\text { "Fornecer ao educando conceitos sobre }[\ldots . .] " \\
\text { "Possibilitar ao educando realizar a }[\ldots] "\end{array}$ \\
\hline A34 & $\begin{array}{l}\text { "Oferecer subsídios teóricos e experiências para que o aluno } \\
\text { compreenda e construa um conceito de Arte compatível com } \\
\text { sua realidade histórica e cultural" }\end{array}$ \\
\hline A41 & "Introduzir conceitos $[\ldots] "$ \\
\hline A44 & $\begin{array}{l}\text { "Possibilitar ao educando a compreensão dos conceitos }[\ldots] " \\
\text { "Possibilitar ao educando conhecer }[\ldots . .] " \\
\text { "Fornecer ao aluno o conhecimento }[\ldots] " \\
\text { "Fornecer ao aluno habilidades práticas e teóricas }[\ldots] " \\
\text { "Possibilitar ao educando o conhecimento [...]" }\end{array}$ \\
\hline A45 & "Possibilitar ao educando a aprendizagem [...]" \\
\hline
\end{tabular}




\begin{tabular}{|c|c|}
\hline Planos de & Unidades de significado \\
\hline & $\begin{array}{l}\text { "Propiciar ao aluno o conhecimento aprendizagem }[\ldots] " \\
\text { "Fornecer ao aluno a habilidade em conhecer aprendizagem } \\
{[\ldots] " \text { "Proporcionar ao aluno a habilidade aprendizagem }[\ldots] "}\end{array}$ \\
\hline A51 & "Possibilitar ao educando a compreensão dos conceitos[...]" \\
\hline A54 & $\begin{array}{l}\text { "Obter conhecimento em todas as operações de manipulação } \\
{[\ldots] "}\end{array}$ \\
\hline A59 & "Proporcionar aos discentes conhecimentos $[\ldots] "$ \\
\hline A62 & "Possibilitar ao educando o entendimento [...]" \\
\hline A70 & $\begin{array}{l}\text { "Possibilitar ao educando a compreensão dos conceitos de } \\
\text { algoritmos [...]" }\end{array}$ \\
\hline
\end{tabular}

Fonte: planos de ensino A1 a A70.

O proposto nas unidades de significado descritas, enquanto obstáculo da transmissão de conhecimentos leva-nos a perceber o planejamento de uma aula em que o aluno recebe o conteúdo de forma passiva. Por outro lado, o professor parece-nos o "dono" do conhecimento, aquele que transmite o saber. Em nossa análise esse conhecimento parece estar "pronto" em algum lugar e, no desenvolvimento da aula, será “possibilitado, propiciado, fornecido, introduzido, permitido e oferecido" ao aluno.

Encontramos em Bachelard (1996) algumas reflexões sobre a ação do professor, as quais julgamos ser importantes a nossa discussão, uma vez que entendemos que poderão se configurar em obstáculo para a constituição do conhecimento nos cursos pesquisados.

[...] para que a ciência objetiva seja plenamente educadora, é preciso que seu ensino seja socialmente ativo. É um alto desprezo pela instrução $\mathrm{o}$ ato de instaurar, sem recíproca, a inflexível relação professor-aluno. A nosso ver, o princípio pedagógico fundamental da atitude objetiva é: Quem é ensinado deve ensinar. Quem recebe instrução e não a transmite terá um espírito formado sem dinamismo nem autocrítica. Nas disciplinas científicas principalmente, esse tipo de instrução cristaliza no dogmatismo o conhecimento que deveria ser um impulso para a descoberta. Além disso, não propicia a experiência psicológica do erro humano (BACHELARD, 1996, p.258). 
Pela compreensão de nossos estudos o conhecimento deve ser construído por docentes e discentes. Todavia tal saber nunca será definitivo, deve estar em constante retificação, o que contradiz o exposto nos documentos analisados. Seja a que nível for da educação, o psiquismo humano deve ser permanentemente remetido para a sua tarefa essencial de invenção, de atividade de abertura (BACHELARD, 1978, p. 93).

Além dos apontamentos sobre a relação professor-aluno e a transmissão de conhecimentos, compreendemos ainda que quando o conhecimento é transmitido ele deixa de ser questionado, não havendo mais necessidade de busca e de retificação de saberes. O obstáculo ao conhecimento instaura-se pela cristalização dos erros não julgados e não questionados, uma vez que houve uma transmissão de saberes.

[...] Os professores de ciências imaginam que o espírito começa como uma aula, que é sempre possível reconstruir uma cultura falha pela repetição da lição, que se pode fazer entender uma demonstração repetindo-a ponto por ponto. Não levam em conta que o adolescente entra na aula de física com conhecimentos empíricos já construídos: não se trata portanto, de adquirir uma cultura experimental, mas sim de mudar de cultura experimental, de derrubar os obstáculos já sedimentados pela vida cotidiana (BACHELARD, 1996, p. 23).

A epistemologia bachelardiana negava todo conhecimento estático e imóvel, uma vez que o conhecimento científico deve formar-se contra um conhecimento anterior. A ideia expressa nas unidades descritas traz um sentido contrário à mobilidade e plasticidade do conhecimento. "Conhecemos sempre contra um conhecimento anterior, retificando o que se julgava sabido e sedimentado. Por isso, não existem verdades primeiras, apenas os primeiros erros: a verdade está em devir [...] (LOPES, 1990, p.254)".

Nesse contexto, para o filósofo Bachelard a tarefa mais difícil na construção do conhecimento é a vigília que se deve ter quanto à constante mobilização do saber. Todo conhecimento imóvel e estático deve ceder lugar 
a um conhecimento aberto e dialetizador, sobretudo na constituição do conhecimento científico e no processo educativo. O espírito científico deve passar de um conhecimento a outro, julgando os conhecimentos anteriores, carregados de subjetividades e preconceitos que retardam a evolução da ciência.

Ora, como o conhecimento objetivo nunca está terminado, como objetos novos vêm continuamente trazer assuntos a discutir no diálogo do espírito e das coisas, todo ensino científico, se for vivo, estará sujeito ao fluxo e refluxo do empirismo e do racionalismo. De fato, a história do conhecimento científico é uma alternativa sempre renovada de empirismo e de racionalismo (BACHELARD, 1996, p.260).

Por esse entendimento a evolução da ciência acontece por meio das constantes rupturas com os erros do passado, negando o já conhecido, desconstruindo o construído em um constante processo descontínuo. $\mathrm{Na}$ concepção de Bachelard o conhecimento científico é comprometido pela continuidade dos saberes, pois nessa linearidade não podemos julgar nossos conhecimentos anteriores à luz da verdade do presente e os obstáculos epistemológicos são cristalizados. Entendemos ainda que a não retificação dos conhecimentos anteriores pode trazer consigo vários outros entraves ao saber científico, tais como a experiência primeira, as generalizações, o senso comum e outros conhecimentos baseados numa cultura geral acumulada pela vida cotidiana.

Bachelard (1978) entende que o saber precisa ser questionado e propõe um novo espírito científico, que se expressa por meio dos processos educativos quando o mestre se propõe a formar o sujeito e não apenas transmitir o que aprendeu.

Esse pensamento fundamenta-se na recusa daquilo que, de modo sedutor, se impõe à cultura científica sob a forma dos primeiros pensamentos, nascidos a partir de observações e colocados sempre antes e acima da crítica. Para o espírito científico, a exatidão é o único aspecto a ser considerado pela percepção, no entanto, essa certeza deve ser rapidamente colocada em 
suspenso em nome de objeções comandadas pela razão, que se dirige à abstração. Um obstáculo ao pensamento científico pode se configurar em toda experiência que se pretende concreta e real, natural e imediata. Isso se deve ao fato de que o ato de conhecer se dá sempre contra um conhecimento anterior que se coloca como abjeção em relação à investigação a ser desenvolvida ou à hipótese a ser confirmada.

É preciso negar a experiência antiga, o que não configura uma negação definitiva, uma vez que os princípios sempre serão dialetizados para constituir novos conhecimentos. Na ciência, as hipóteses verdadeiramente científicas, para serem validadas, precisam esbarrar em contradições. Do mesmo modo, no processo educativo, as experiências precisam retificar erros, promover discussões, ou então serão inúteis. Para Bachelard o pensamento científico é caracterizado, sobretudo, pelos erros retificados. A experiência, quando não é construída pelos erros retificados solidifica-se como um fato. A ausência da verificação e do confronto de uma verdade com outros diferentes pontos de vista bloqueia a criação de leis ou a confirmação cientifica de algo como verdade.

Nesse sentido, a leitura desse epistemólogo levou-nos a refletir sobre a educação. De suas reflexões chamou-nos a atenção, o seu original conceito de formação humana. De acordo com Barbosa e Bulcão (2011), as reflexões bachelardianas não se referem ao termo educação, comprometido com a postura escolar de transmissão de conhecimento, mas nos a remete a formação, o que na verdade é uma acepção de metamorfose, de transformação, pois o homem aspira ser mais, deseja ascender ao que não é movido por seus devaneios. Assim, a imaginação criadora tem importante papel no processo formativo. Ao comentar esse aspecto do pensamento do filósofo de Bar-sur-Aube, uma autora afirma:

Uma das dimensões da importância do pensamento de Gaston Bachelard para o campo de estudos da Educação é o acontecimento da aprendizagem enquanto viabilizadora de uma experiência de metamorfose, de formação e de transformação humana. O filósofo da imaginação lembra que o aluno não vem à escola para adquirir uma 
cultura, ele vem para transformar sua cultura, para demolir os obstáculos já cristalizados pela vida cotidiana. O filósofo da imaginação defende ainda que é na escola que o sujeito busca demolir os obstáculos já cristalizados pela vida cotidiana (ABREU-BERNARDES, 2010, p. $14)$.

O questionamento do saber construído não se refere, portanto, apenas à ciência ou à filosofia de um modo geral, mas igualmente contempla a cultura que o aluno traz para a escola e que esse mesmo aluno quer transformar.

O pensamento bachelardiano concebe a educação por uma visão racionalista, crítica e reflexiva. Tal pensamento é livre, no entanto comprometido com a formação. Para o filosofo-professor a educação, na verdade, deve ser uma formação, caracterizada pelo processo de construção e desconstrução permanente do espírito científico. Entendemos que esse pensamento descarta qualquer tipo de interesse econômico ou de instrução dualista.

\section{Conclusão}

$\mathrm{Na}$ interrogação do sentido atribuído ao objeto investigado percebemos que os possíveis obstáculos epistemológicos identificados nos documentos analisados se inter-relacionam. Um bloqueio ao conhecimento pode gerar outro entrave à evolução do saber que por sua vez está relacionado a outros obstáculos ao progresso do conhecimento.

Os erros ocorridos ao longo da construção da ciência, que foram omitidos ou desconhecidos, podem apontar os vários obstáculos epistemológicos surgidos na história, possibilitando uma melhor compreensão do conhecimento construído. Pensamos que tal reflexão pode ser aplicada à prática educativa, ou seja, a reflexão acerca dos erros no ato de conhecer podem identificar os obstáculos inerentes a um determinado conhecimento. Um novo saber somente poderá ser constituído após a superação das ideias elaboradas anteriormente, permeadas de mitos, crenças e valores com base no senso comum. 
A identificação dos entraves à construção do conhecimento científico foi realizada por meio da análise das reais condições do conhecimento e do julgamento desses saberes à luz da verdade de hoje. Dessa forma, identificamos ações planejadas que podem configurar-se em obstáculos ao saber onde pensávamos haver somente conhecimento.

No caso da presente pesquisa, de modo geral, percebemos a supervalorização da formação profissionalizante nos documentos analisados. Tal fato pode ser identificado nas 15 unidades de significado citadas que remetem ao aprimoramento profissional e ao mercado de trabalho. Essa finalidade educativa, se concebida no ato de planejar uma aula, pode culminar em entraves ao conhecimento, sobretudo no conhecimento utilitário.

Enfatizamos que demonstramos apenas aquilo que nos planejamentos podem bloquear a constituição de saberes na prática educativa nos cursos técnicos integrados ao ensino médio. No entanto, há situações que podem descaracterizar ou confirmar tais identificações, uma vez que não tivemos contato direto com a sala de aula, apenas nos aproximamos da prática em que professor e aluno devem construir juntos o saber.

Mesmo com tais considerações entendemos que a presença dos obstáculos ao conhecimento é inevitável em todo processo de construção do saber, ao considerarmos que é a partir da superação deles que o conhecimento evolui. O estágio em que hoje se encontram os documentos analisados pode ser superado e futuramente novos ideários serão construídos, tomando lugar nos planos de ensino ora analisados.

Entendemos que nosso olhar sobre os documentos analisados trata-se de uma primeira reflexão a partir da epistemologia bachelardiana. Todavia, tal ideário aponta novos questionamentos a partir do que foi percebido e analisado. Conforme postula Bachelard, são esses questionamentos que nos levam a buscar a identificação e possível superação dos obstáculos ao conhecimento no exercício da prática pedagógica. 


\section{Referências}

ABREU-BERNARDES, S. T. A poética na formação humana na perspectiva teórica de Gaston Bachelard. Reunião Anual da Associação Nacional de PósGraduação e Pesquisa em Educação (ANPED), 33. Caxambu, MG, 2010. Anais..., Caxambu, MF, ANPED, 2010. CD-ROM, 1, p. 14. Disponível em: http://www.anped.org.br/33encontro/app/webroot/files/file/Trabalhos $\% 20$ em\%20PDF/GT24-6419--Int.pdf Acesso em: 16 jan. 2012.

BACHELARD, G. A formação do espirito cientifico: contribuição para uma psicanálise do conhecimento. Tradução Estela dos Santos Abreu. Rio de Janeiro: Contraponto 1996.

- A filosofia do não. Trad. Remberto Francisco Kuhnen, Antônio da Costa Leal, Lídia do Valle Santos Leal. São Paulo: Abril Cultural, 1978a. (Coleção Os Pensadores).

- Epistemologia. Trad. Nathanael C. Caixeiro. Textos organizados por Dominique Lecourt. Lisboa: Setenta, 1984.

O novo espirito científico. Trad. Remberto Francisco Kuhnen, Antônio da Costa Leal, Lídia do Valle Santos Leal. São Paulo: Abril Cultural, 1978b. (Coleção Os Pensadores).

- A água e os sonhos: ensaio sobre a imaginação da matéria. São Paulo: Martins Fontes, 1998.

BICUDO, M. A. V. Sobre a fenomenologia. In: BICUDO, M. V.; ESPÓSITO, V. H. C. (Orgs). A pesquisa qualitativa em educação: um enfoque fenomenológico. Piracicaba: Editora Unimep, p.15-22, 1994.

Fenomenologia: confrontos e avanços. São Paulo (SP): Cortez, 2000.

BRASIL. Lei $n^{\circ}$. 11.892, de 29 de dezembro de 2008. Institui a Rede Federal de Educação Profissional, Científica e Tecnológica, cria os Institutos Federais de Educação, Ciência e Tecnologia, e dá outras providências. Diário Oficial da União, Brasília, DF, 30 dez. 2008. Seção 1, p. 1.

Decreto $n^{\circ} 5.154$, de 23 de julho de 2004. Regulamenta o $₫ 2^{\circ}$ do art. 36 e os arts. 39 a 41 da Lei 9.394, de 20 de dezembro de 1996, que estabelece as diretrizes e bases da educação nacional e dá outras providências. Diário Oficial da União, Brasília, DF, 2004. 
BULCÃO, M. O racionalismo da ciência contemporânea: uma análise da epistemologia de Gaston Bachelard. Rio de Janeiro: Edições Antares, 1981.

CIAVATA, M. e RAMOS, M. Ensino Médio e Educação Profissional no Brasil: dualidade e fragmentação. Retratos da Escola - Revista da Escola de Formação da Confederação Nacional dos Trabalhadores em Educação, Brasília- v. 5, n. 8, semestral, p.27-41, 2011. Disponível em

http://sinproesemma.org.br/dados/arquivos/revista_esforce_n_8_jan_jun_20 11.pdf. Acesso em 17 mar. 2013.

FRIGOTTO, G. A relação da educação profissional e tecnológica com a universalização da educação básica, Educação e Sociedade. Campinas, v. 28, n. 100 - Especial, p. 1129-1152, out. 2007. Disponível em http://www.cedes.unicamp.br. Acesso em 10 de mar. de 2013.

Qual é a cara do Ensino Médio brasileiro? 2009. Portal emdiálogo Observatórios Jovem da UFF e da Juventude da UFMG. Disponível em http://www.emdialogo.uff.br/node/487. Acesso em 10 de abr. de 2013.

. Os circuitos da história e o balanço da educação no Brasil na primeira década do século XXI. Revista Brasileira de Educação v. 16 n. 46, p. 235-274. janabr. 2011. Disponível em http://www.scielo.br/pdf/rbedu/v16n46/v16n46a13.pdf. Acesso em 10 abr. 2013.

KUENZER, A. Ensino médio e profissional: as políticas do estado neoliberal. São Paulo: Cortez, 1997. (Questões da Nossa Época).

LOPES, A. R. C. Livros didáticos: obstáculos ao aprendizado da ciência química. 1990. 289 p. Dissertação (Mestrado em Educação) Instituto de Estudos Avançados em Educação da Fundação Getúlio Vargas, Rio de Janeiro. 1990. Disponível em http://bibliotecadigital.fgv.br/dspace/handle/10438/9089. Acesso em 16 abr.2012.

LÜDKE, M., ANDRÉ, M. E. D. A. Pesquisa em educação: abordagens qualitativas. São Paulo, EPU, 1986.

MACEDO, A. S. de G. A Pesquisa em educação no Brasil no contexto do pensamento epistemológico de Gaston Bachelard. 2006. 167 p. Tese (Doutorado em Educação) Faculdade de Educação, Universidade do Estado do Rio de Janeiro, Rio de Janeiro, 2006. Disponível em 
http://www.proped.pro.br/teses/teses_pdf/2002_1-4-do.pdf. Acesso em 05 abr. 2012.

SCHMIDT, M. A. Os institutos de educação, ciência e tecnologia: um estudo da expansão da rede federal de educação profissional e tecnológica. 2010. 155 p. Dissertação (Mestrado em educação) Faculdade de Educação - Universidade de Passo Fundo, Passo Fundo, 2010. Disponível em http://www.dominiopublico.gov.br/pesquisa/DetalheObraForm.do?select_ac tion=\&co_obra=193317. Acesso em 5 fev. 2013. 